\title{
LINFOMA DE CÉLULAS T ASOCIADO CON ENTEROPATÍA TIPO II
}

Cristian J. Pérez H. M D*, Paula Castro**, J osé Fernando Polo M D***, Patricia López M D****, Edgardo Yaspe M D*****

\section{Resumen}

El linfoma de células $\mathbf{T}$ asociado con enteropatía tipo II es una rara variante del $\mathbf{T}$ periférico, el cual se puede ubicar en intestino delgado y presenta características inmunofenotípicas específicas. El presente estudio relata el caso de un hombre de 46 años sin antecedentes médicos que presentó perforación del intestino delgado con posterior diagnóstico por histopatología de un linfoma de células $T$ asociado con enteropatía tipo II.

Palabras clave: linfoma, CD56, intestino, células T.

\section{TYPE II ENTEROPATHY-ASSOCIATED T-CELL LYMPHOMA}

\section{Abstract}

Type II enteropathy-associated T-cell lymphoma is a rare type of peripheral T-cell lymphoma that may involve the small intestine and has specific immunophenotypic features. This study reports the case of a 46-year old male with no history of previous illnesses who presented a small intestine perforation. A hispathologic diagnosis of type II enteropathy-associated T-cell lymphoma was made.

Key words: lymphoma, CD56, intestine, T cells

Fecha recibido: mayo 5 de 2014 - Fecha aceptado: octubre 17 de 2014

* Residente Il de Patología. Fundación Universitaria de Ciencias de la Salud. Bogotá DC, Colombia.

** Estudiante de Medicina. Fundación Universitaria de Ciencias de la Salud. Bogotá DC, Colombia.
*** Instructor Asociado, Coordinador del Servicio de Patología, Fundación Universitaria de Ciencias de la Salud. Bogotá DC, Colombia. Hospital Infantil Universitario de San José. Bogotá DC, Colombia.

***** Patólogo. Instructor Asistente. Fundación Universitaria de Ciencias de la Salud. Bogotá DC, Colombia.

****** Médico oncopatólogo. Profesor Asistente. Fundación Universitaria de Ciencias de la Salud. Bogotá DC, Colombia. 


\section{Introducción}

EI linfoma de células T asociado con enteropatía tipo II (LCTAE) es una neoplasia de origen linfoide de curso clínico agresivo, cuya afectación primaria radica en el tracto gastrointestinal, sin importar su origen 0 extensión. ${ }^{1}$ Los linfomas de células $T$ asociados a enteropatía los clasifica la Organización M undial de la Salud en dos tipos, el I asociado con enfermedad celíaca que es CD8 y CD 56 negativo, mientras el tipo II no tiene asociación y es predominantemente CD 8 y CD56 positivo. ${ }^{2}$

Dentro del diagnóstico diferencial de las enfermedades linfoproliferativas del tracto gastrointestinal CD56 positivas se encuentran el linfoma de células T/NK primario intestinal (tipo nasal), el de células T asociado con enteropatía tipo II (LCTAE) y el de células T hepatoesplénico. ${ }^{3,4}$ De estas enfermedades, el linfoma de células T/NK tipo nasal primario intestinal y el LCTAE se pueden presentar como lesiones del tracto gastrointestinal, pero el T/NK expresa CD 56, es negativo para CD 8 y positivo para el virus de Epstein $B$ arr (VEB ). EI LCTAE tiene mal pronóstico con informes en la literatura de supervivencia a dos años del $28 \%$. 3,4,5 R eportamos un caso sin antecedentes médicos con una neoplasia linfoproliferativa de células $T$ que debuta con perforación intestinal, la cual es reactiva en los estudios de inmunohistoquímica para CD 8 y CD56, entidad rara en nuestro medio que merece especial atención por el comportamiento clínico agresivo.

\section{Presentación del caso}

Hombre de 46 años de edad que consulta a urgencias por dolor abdominal generalizado de quince días de evolución, diarrea con moco y sin sangre, tratado en un centro de primer nivel con analgésicos sin mejoría clínica. Niega todo tipo de antecedentes personales y familiares. En la clínica se evidencia abdomen blando, depresible, con dolor a la palpación en hipogastrio, signo de Blumberg positivo y ruidos intestinales insinuados. Se inicia tratamiento con meperidina y líquidos endovenosos. Se ordenó una ultrasonografía de abdomen total en la que se observó abundante cantidad de líquido libre en cavidad peritoneal incluyendo pelvis menor, goteras parietocólicas, perihepático y periesplénico. En el hemograma hay leucopenia de $1.900 / \mathrm{mm}^{3}$ a expensas de neutrófilos con hemoglobina de $14 \mathrm{~g} / \mathrm{dL}$ hematocrito de $48.1 \%$ y recuento plaquetario normal. $L$ a radiografía de tórax reveló ascenso de los hemidiafragmas con disminución no homogénea de la transparencia en las bases, debido a densidades lineales largas y gruesas compatibles con bandas de atelectasia plana, escasa cantidad de líquido en la base derecha que se extiende a lo largo de las cisuras y una pequeña cámara de neumoperitoneo de localización subdiafragmática derecha.

Por los hallazgos en la ecografía abdominal y en la radiografía de tórax se considera realizar al paciente una laparotomía exploratoria, en donde se halla una masa que compromete el segmento del meso del intestino del gado, con perforación del mismo que abarca el $100 \%$ de la circunferencia, asociada con peritonitis generalizada y plastrón con necrosis del epiplón mayor; se realiza resección segmentaria de intestino delgado y se envía la pieza quirúrgica para estudio anatomopatológico (Figura 1, A y B).
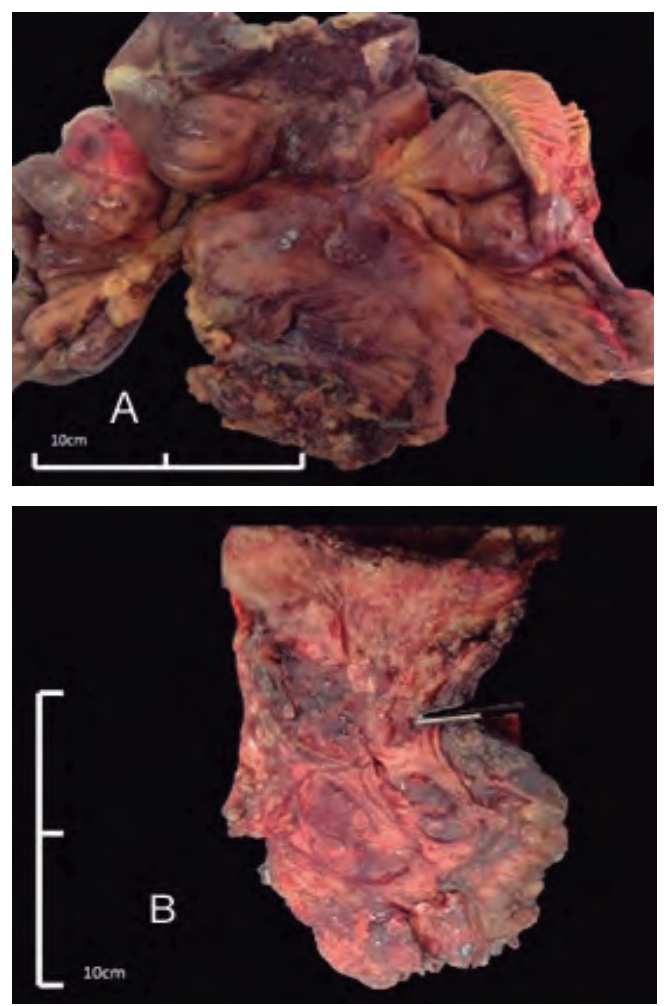

Figura I. Espécimen quirúrgico que muestra masa en mesenterio $(A)$, que se extiende hacía la mucosa $(B)$. 
EI análisis reveló la pared del intestino del gado infiltrada en su totalidad por una lesión tumoral maligna constituida por células de tamaño intermedio con núcleos grandes, hipercromáticos, pleomórficos con nucléolo prominente y frecuentes mitosis (Figuras 2,3 y 4). La mucosa intestinal adyacente no muestra alteración de la relación cripta/vellosidad, aumento de los linfocitos intraepiteliales ni borramiento del borde en cepillo (Figuras 5 y 6). L os estudios de inmunohistoquímica en las células tumorales son positivas para

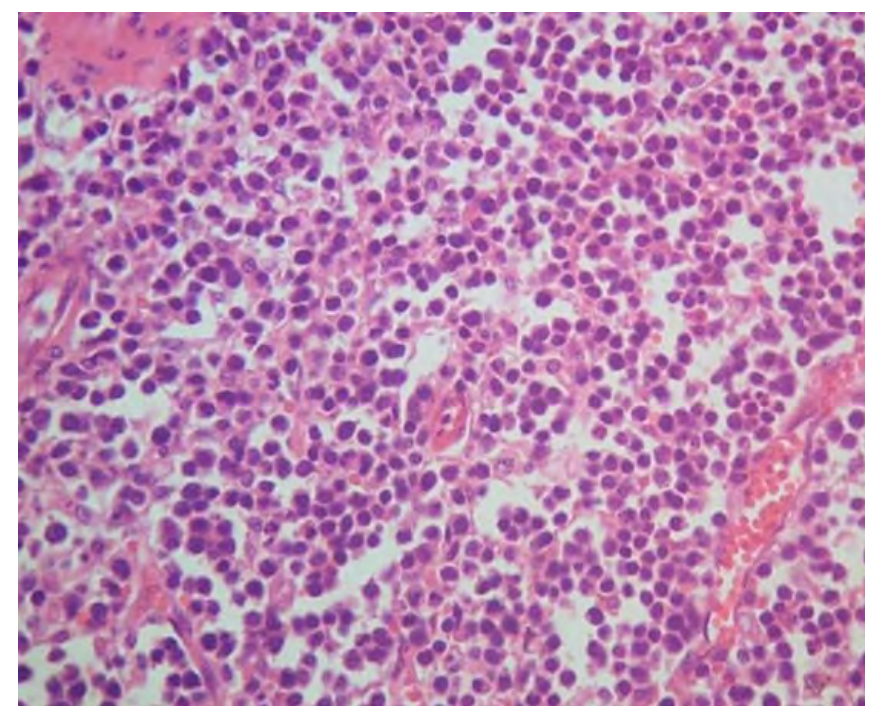

Figura 2. Neoplasia constituida por células de tamaño intermedio con núcleos grandes, hipercromáticos, pleomórficos con nucléolo prominente y frecuentes mitosis.

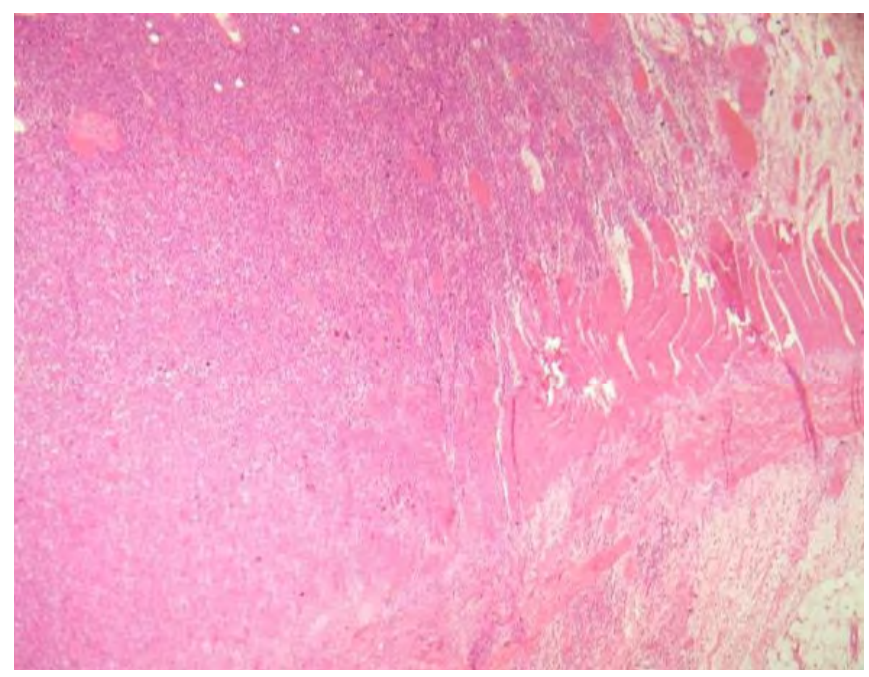

Figura 3. El tumor infiltra todas las capas del intestino.
CD3, BCL-2, CD 7, CD8 y CD56, con un índice de proliferación celular K i-67 del 95\% (Figura 7); CD4 y L M P-1 fueron negativos.

Dados los antecedentes del paciente, la presentación clínica y los hallazgos histológicos y de inmunohistoquímica se diagnosticó un linfoma de células T asociado con enteropatía tipo II, por lo cual, el paciente es remitido a otra institución para ser evaluado por oncología y continuar el tratamiento para su enfermedad.

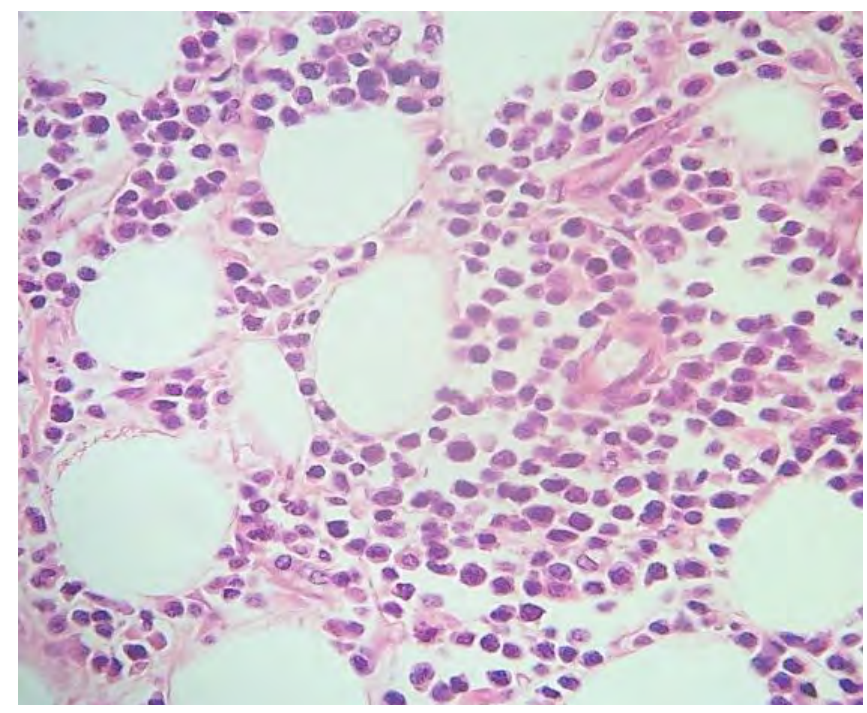

Figura 4. Las células neoplásicas junto con los adipocitos del mesenterio.

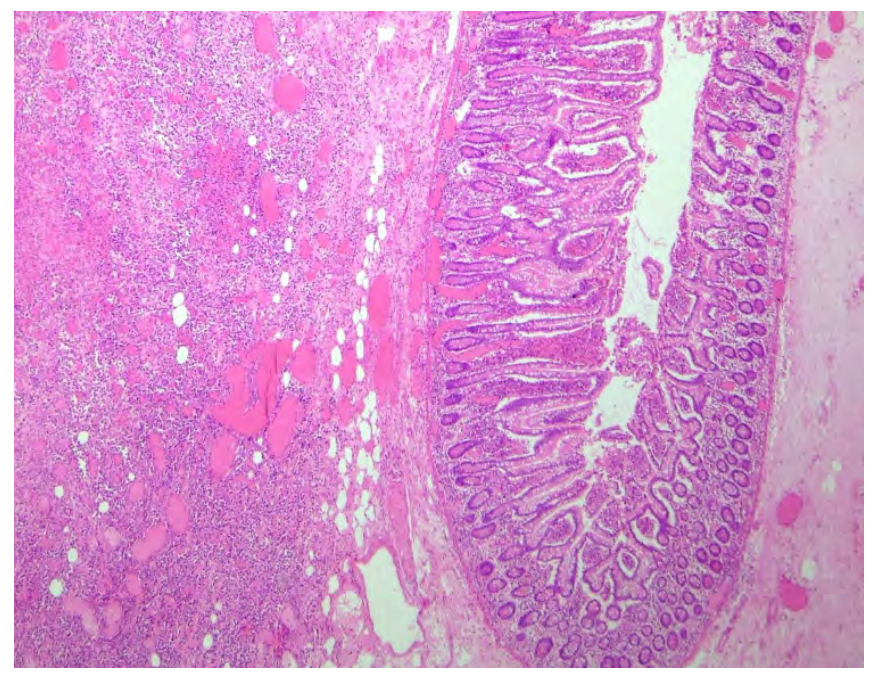

Figura 5. La mucosa intestinal adyacente al tumor no muestra alteración de la arquitectura. 


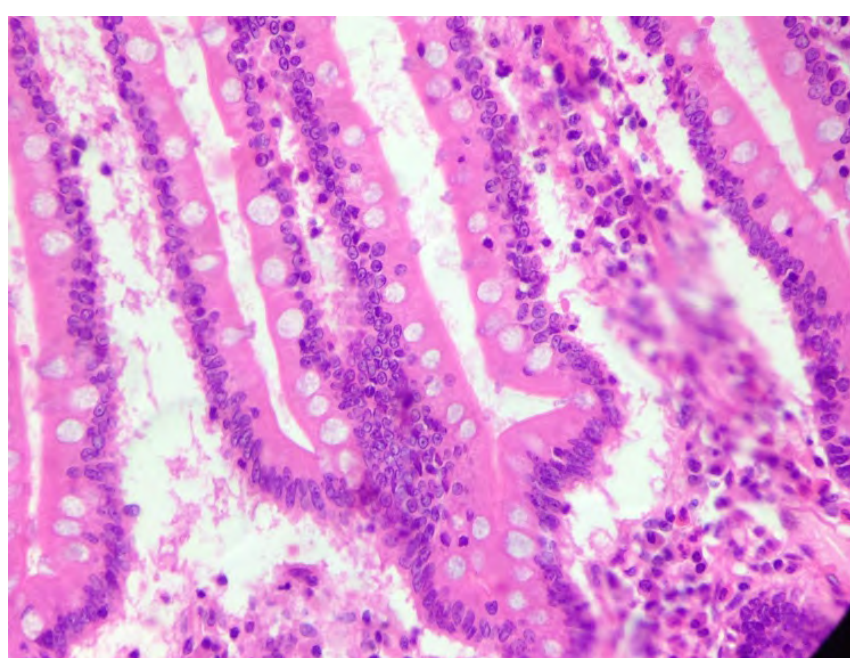

Figura 6. El epitelio intestinal conserva el borde en cepillo y no hay aumento de los linfocitos intraepiteliales.

\section{Disc usión}

El linfoma de células T asociado con enteropatía tipo II es una neoplasia compuesta de linfocitos T maduros. Su prevalencia es baja, pues constituye menos del $5 \%$ de los linfomas intestinales. Es raro en los países occidental es aunque tiene una al ta prevalencia en Europa del norte por lo que se cree que hay una base genética para desarrollar esta enfermedad. La mayoría ocurre en hombres en la sexta década de la vida. ${ }^{6}$

El diagnóstico es difícil por la sintomatología inespecífica. Son neoplasias de mal pronóstico debido a las complicaciones y que por lo general se identifican en estado avanzado; los pacientes que han sobrevivido hasta cinco años después del diagnóstico ha sido debido a tratamiento con quimioterapia después de la resección quirúrgica.

Este linfoma hace metástasis por vía hematógena a hígado, bazo, sistema gastrointestinal, pulmón y piel. ${ }^{6.7,8}$ En la macroscopía la zona del intestino que se encuentra afectada está dilatada y edematosa al ternando con otras ulceradas $y / 0$ estenosadas. ${ }^{8} \mathrm{Al}$ microscopio se caracterizan por presentar infiltrado de células monomorfas de tamaño pequeño 0 intermedio que puede afectar todas las capas de la pared del intestino sin un patrón angiocéntrico y los cambios morfológicos atribuibles a la enteropatía por glúten no están presentes. ${ }^{8}$ En cuanto a la inmunohistoquímica, muestran

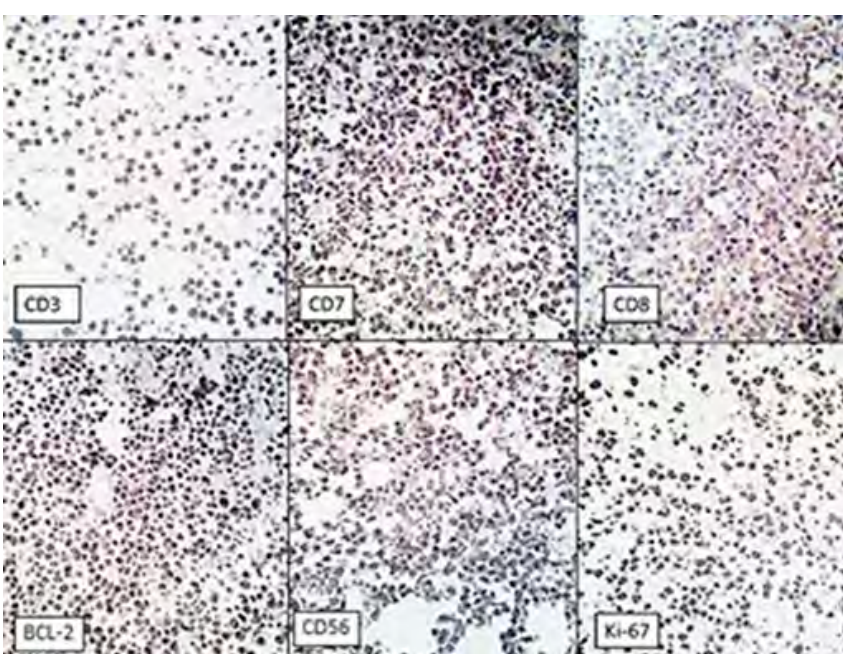

Figura 7. Las células neoplásicas son positivas para CD3, BCL-2, CD7, CD8 y CD56, con un índice de proliferación celular $\mathrm{Ki}-67$ del $95 \%$.

un inmunofenotipo positivo para CD 3, CD 7, CD 8 y CD56. Este último ha sido reconocido como marcador específico pero no sensible, por lo que se considera que su expresión es diagnóstica para este tipo de linfoma. ${ }^{8}$

A I revisar la literatura la mayoría de casos de linfomas de células T se encuentran reportados en países asiáticos, en especial China, Japón y Taiwán; los pocos americanos se han informado sobre todo en M éxico. En Colombia no hay reportes sobre el tema y esta publicación es una invitación para conocer más casos de este tipo y recordar que el diagnóstico temprano proporciona un tratamiento rápido y adecuado.

\section{Referencias}

1. Zettl A, de Leeuw R, Haralambieva E, Mueller-Hermelink HK. Enteropathy type T- cell lymphoma. Am J Clin Pathol. 2007;127:701-6.

2. Chim CS, Au WY, Shek TW, Ho J, Choy C, Ma SK, et al. Primary CD56 positive lymphomas of the gastrointestinal tract. Cancer. 2001; 91:525-33.

3. Ko YH, Cho EY, Kim JE, Lee SS, Huh JR, Chang HK, et al. NK and NK - like $\mathrm{T}$ - cell lymphoma in extra nasal sites: a comparative clinicopathological study according to site and EBV status. Histopathology. 2004; 44:480-9.

4. Tung CL, Hsieh PP, Chang JH,Chen RS, Chen YJ, Wang JS. Intestinal T - cell and natural killer - cell lymphomas in Taiwan with special emphasis on 2 distinct cellular types: natural killer - like cytotoxic T cell and true natural killer cell. Hum Pathol. 2008; 39:1018-25.

5. Kim TM, Lee SY, Jeon YK, Ryoo BY, Cho GJ, Hong YS, et al. Clinical heterogeneity of extranodal NK/T - cell lymphoma, nasal type: a national survey of the Korean Cancer Study Group. Ann Oncol. 2008; 19:1477-84.

6. Banks PM. Gastrointestinal lymphoproliferative disorders. Histopathology. 2007 Jan; 50:42-54

7. Fenoglio-Preiser CM, Noffsinger AE, Stemmermann GN, Lantz P, Isaacson P. Gastrointestinal pathology: an atlas and text. Philadelphia: Lippencott Williams; 2007.

8. Hamilton SR, Aaltonen LA, editors. Pathology and Genetics of Tumours of the Digestive System. Lyon: World Health Organization Classification of Tumours; IARC Press; 2000 